\title{
Metaplasticity: A Promising Tool to Disentangle Chronic Disorders of Consciousness Differential Diagnosis
}

\author{
Antonino Naro*, Alessia Bramanti*, Antonino Leo*, \\ Placido Bramanti* and Rocco Salvatore Calabrò ${ }^{*}, \dagger, \dot{\dagger}$ \\ *IRCCS Centro Neurolesi "Bonino-Pulejo", Messina, Italy \\ ${ }^{\dagger}$ S.S. 113, Contrada Casazza, 98124 Messina, Italy \\ ¥salbror7@tiscali.it
}

Accepted 25 November 2017

Published Online 26 January 2018

\begin{abstract}
The extent of cortical reorganization after brain injury in patients with Vegetative State /Unresponsive Wakefulness Syndrome (UWS) and Minimally Conscious State (MCS) depends on the residual capability of modulating synaptic plasticity. Neuroplasticity is largely abnormal in patients with UWS, although the fragments of cortical activity may exist, while patients MCS show a better cortical organization. The aim of this study was to evaluate cortical excitability in patients with disorders of consciousness (DoC) using a transcranial direct current stimulation (TDCS) metaplasticity protocol. To this end, we tested motor-evoked potential (MEP) amplitude, short intracortical inhibition (SICI), and intracortical facilitation (ICF). These measures were correlated with the level of consciousness (by the Coma Recovery Scale-Revised, CRS-R). MEP amplitude, SICI, and ICF strength were significantly modulated following different metaplasticity TDCS protocols only in the patients with MCS. SICI modulations showed a significant correlation with the CRS-R score. Our findings demonstrate, for the first time, a partial preservation of metaplasticity properties in some patients with DoC, which correlates with the level of awareness. Thus, metaplasticity assessment may help the clinician in differentiating the patients with DoC, besides the clinical evaluation. Moreover, the responsiveness to metaplasticity protocols may identify the subjects who could benefit from neuromodulation protocols.
\end{abstract}

Keywords: Metaplasticity; TDCS; UWS; MCS; consciousness.

\section{Introduction}

The human brain networks have a remarkable property to maintain the stability of neural functions and their synaptic excitability and plasticity through homeostatic mechanisms. ${ }^{1}$ This finely-tuned plasticity regulation keeps neural activity within a dynamic range concerning many functions, including brain damage recovery. ${ }^{[2] 5]}$ This avoids the development of uncontrolled and maladaptive plasticity (including the overexpression of long-term potentiation LTP - and depression — LTD - mechanisms).
These homeostatic mechanisms include metaplasticity, a term originally proposed by the theoretical physicist Cooper in $1982 \stackrel{6}{6}$ Metaplasticity adjusts the ongoing threshold for LTP and LTD induction depending on the previous synaptic activity, 12.7] 12 and balancing different types of influencing factors, including acute stress and related hormones, and addicting factors, $\frac{13}{16}$ thus altering the magnitude and duration of the subsequent synaptic events. In this way, metaplasticity avoids synaptic activity saturation and endows neural networks

\footnotetext{
${ }_{\ddagger}$ Corresponding author.

This is an Open Access article published by World Scientific Publishing Company. It is distributed under the terms of the Creative Commons Attribution 4.0 (CC-BY) License. Further distribution of this work is permitted, provided the original work is properly cited.
} 
with an ongoing ability to respond to an everchanging environment and to update continuously the information storage capacity. These properties are fundamental concerning several functions, including consciousness 1718 and brain damage recovery $2-7.19$

Metaplasticity can be experimentally investigated following two consecutive neuromodulation protocols: priming and conditioning $\cdot \frac{3}{3}$ Generally speaking, the former (including noninvasive brain stimulation) modifies the after-effects of the latter but the direction of such effects depends on the targeted synapses. When priming and conditioning focus on the same synapses, metaplasticity occurs homosynaptically by the means of mechanisms dependent on the $N$-methyl- $D$-aspartate receptor (LTP prevention) or metabotropic glutamate receptor (LPT fostering) ${ }^{20}$ Otherwise, metaplasticity occurs heterosynaptically, leading to the LTP inhibition and LTD facilitation. $21 / 22$

Among the noninvasive brain stimulation tools, Transcranial Direct Current Stimulation (TDCS) has been proposed to interfere with LTP and LTD-

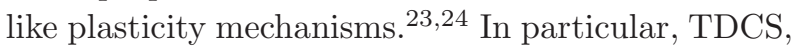
which consists of low constant currents delivered through small surface electrodes, can either depolarize (anodal TDCS) or hyperpolarize (cathodal TDCS) neuron's resting membrane, thereby increasing or decreasing the cortical excitability, respectively. ${ }^{25}$ Therefore, TDCS is most suitable to study metaplasticity.

The patients suffering from chronic Disorders of Consciousness (DoC), including Minimally Conscious State (MCS) and Vegetative State/Unresponsive Wakefulness Syndrome (UWS), show a large-scale cortico-thalamo-cortical connectivity breakdown and cortical disexcitability, in the reason of the loss of inhibitory tone from the thalamus due to the thalamo-cortical damage ${ }^{26127}$ The degree of cortico-thalamo-cortical connectivity deterioration correlates with the consciousness level and the outcome of DoC individuals. $\frac{28}{}$ Nonetheless, some patients with DoC show cortical excitability and connectivity during noninvasive brain stimulation higher than those expected based on the clinical data 39 In fact, some patients may be misdiagnosed as suffering from UWS ${ }^{32}$ In other words, some patients with DoC do manifest a behavior similar to UWS, but electrophysiologically they are MCS. Thus, these patients are unable to communicate behaviorally, probably due to the specific sensory-motor integration deficits. $\frac{29 \mid 30}{20}$ Therefore, we may hypothesize that noninvasive brain stimulation may unmask residual networks subtending awareness in some patients clinically defined as UWS. However, patients with DoC show a maximal facilitation of excitability and plasticity mechanisms yet at the baseline, in an attempt to regain network functions. ${ }^{33134}$ However, such mechanisms work in a maladaptive manner, i.e. persistently and unadaptably. $\stackrel{35}{5}$ Therefore, some patients with DoC may not show a response to simple noninvasive brain stimulation paradigms, as they cannot cross the threshold for plasticity modifications ${ }^{[28}$ Consequently, such patients remain misdiagnosed. Thus, the use of more complex noninvasive brain stimulation protocols, including those concerning metaplasticity, could be of some help, since complex protocols could entrain more complex networks and plasticity mechanisms. This could be important in keeping with the sensibility of metaplasticity to stressing factors, which are very common in patients with DoC $13-1844$ In this way, it could be possible to unmask the residual connectivity and plasticity properties that may support covert awareness. We studied the effects of a priming and a conditioning TDCS on the premotor and motor cortex metaplasticity of the patients with DoC and correlated clinical and electrophysiological measures to better differentiate the patients with DoC.

\section{Methods}

\subsection{Subjects}

We enrolled 40 patients with DoC (19 with MCS and 21 with UWS) following hypoxic-ischemic or traumatic brain damage, who were compared with 25 healthy control (HC) individuals (14 females and 11 males; mean age $52 \pm 5$ years). The patients met the criteria for vegetative state and MCS diagnosis. ${ }^{36137}$ The detailed demographic and clinical characteristics are reported in Table 10 The exclusion criteria were pre-existing severe neurological or systemic diseases; any critical condition; administration of other modifying cortical-excitability drugs than $L$-Dopa, analgesics, baclofen, and anti-epileptic drugs; epileptic history; the presence of electric/electromechanical devices within head and neck; the presence of electroencephalographic suppression-burst pattern; the 
Table 1. Clinical-demographic characteristics.

\begin{tabular}{|c|c|c|c|c|c|c|c|c|c|c|}
\hline \multirow[b]{2}{*}{$\mathrm{DoC}$} & \multirow{2}{*}{$\begin{array}{l}\text { Etiology, gender, } \\
\text { age, onset }\end{array}$} & \multirow[b]{2}{*}{ MRI } & \multicolumn{8}{|c|}{ CRS-R } \\
\hline & & & Total & $A$ & $V$ & $M$ & $\mathrm{OM}$ & $C$ & $\mathrm{Ar}$ & Treatment \\
\hline \multirow{19}{*}{$\begin{array}{l}\text { MCS } \\
(n=19)\end{array}$} & $T, F, 70 \mathrm{y}, 13 \mathrm{~m}$ & $\mathrm{Fb} \_h$ & $20 \pm 4$ & $4 \pm 1$ & $4 \pm 1$ & $5 \pm 1$ & $3 \pm 1$ & 1 & $3 \pm 1$ & 1 \\
\hline & $A, M, 57 \mathrm{y}, 9 \mathrm{~m}$ & WMH & $19 \pm 4$ & $4 \pm 1$ & $4 \pm 1$ & $5 \pm 1$ & $2 \pm 1$ & 1 & $3 \pm 1$ & $1+2$ \\
\hline & $T, F, 72 \mathrm{y}, 6 \mathrm{~m}$ & FP_h & $18 \pm 4$ & $4 \pm 1$ & $3 \pm 1$ & $4 \pm 1$ & $3 \pm 2$ & 1 & $3 \pm 1$ & $1+3$ \\
\hline & $T, M, 47 \mathrm{y}, 12 \mathrm{~m}$ & FP_h $h$ & $18 \pm 4$ & $3 \pm 1$ & $4 \pm 1$ & $5 \pm 1$ & $2 \pm 1$ & 1 & $3 \pm 1$ & \\
\hline & $T, M, 33 \mathrm{y}, 18 \mathrm{~m}$ & multiple_ $h$ & $12 \pm 2$ & $2 \pm 1$ & $2 \pm 1$ & $3 \pm 1$ & $2 \pm 1$ & 1 & $2 \pm 1$ & 2 \\
\hline & $A, M, 51 \mathrm{y}, 18 \mathrm{~m}$ & WMH & $10 \pm 2$ & $2 \pm 1$ & $2 \pm 1$ & $3 \pm 1$ & $1 \pm 1$ & 1 & $1 \pm 1$ & $1+2$ \\
\hline & $T, F, 44 \mathrm{y}, 3 \mathrm{~m}$ & F_h & $9 \pm 4$ & $2 \pm 1$ & $2 \pm 1$ & $2 \pm 1$ & $1 \pm 1$ & 1 & $1 \pm 1$ & $1+3$ \\
\hline & $T, F, 43 \mathrm{y}, 8 \mathrm{~m}$ & $\mathrm{Fb} \_h$ & $20 \pm 4$ & $4 \pm 1$ & $4 \pm 1$ & $5 \pm 1$ & $3 \pm 2$ & 1 & $3 \pm 1$ & 1 \\
\hline & $A, M, 48 \mathrm{y}, 9 \mathrm{~m}$ & WMH & $19 \pm 4$ & $4 \pm 1$ & $4 \pm 1$ & $5 \pm 1$ & $2 \pm 2$ & 1 & $3 \pm 1$ & $1+2$ \\
\hline & $T, F, 50 \mathrm{y}, 7 \mathrm{~m}$ & FP_h $h$ & $18 \pm 4$ & $4 \pm 1$ & $3 \pm 2$ & $4 \pm 2$ & $3 \pm 3$ & 1 & $3 \pm 1$ & $1+3$ \\
\hline & $A, F, 59 \mathrm{y}, 21 \mathrm{~m}$ & WMH & $18 \pm 1.7$ & $4 \pm 1$ & $4 \pm 1$ & $5 \pm 1$ & $1 \pm 1$ & 1 & $3 \pm 1$ & 1 \\
\hline & $V, F, 65 \mathrm{y}, 29 \mathrm{~m}$ & F_ $h$ & $13 \pm 1.0$ & $3 \pm 1$ & $2 \pm 1$ & $3 \pm 1$ & $1 \pm 3$ & 1 & $3 \pm 1$ & $1+2$ \\
\hline & $T, M, 45 \mathrm{y}, 26 \mathrm{~m}$ & Fb_h & $10 \pm 0.8$ & $3 \pm 1$ & $2 \pm 2$ & $2 \pm 2$ & $1 \pm 1$ & 1 & $1 \pm 1$ & $1+3$ \\
\hline & $V, M, 56 \mathrm{y}, 32 \mathrm{~m}$ & P_IS & $14 \pm 1.5$ & $3 \pm 1$ & $2 \pm 2$ & $5 \pm 2$ & $2 \pm 1$ & 1 & $1 \pm 1$ & \\
\hline & $T, M, 69 \mathrm{y}, 17 \mathrm{~m}$ & FP_ $h$ & $12 \pm 0.9$ & $2 \pm 1$ & $3 \pm 1$ & $3 \pm 1$ & $1 \pm 3$ & 1 & $2 \pm 1$ & $2+3$ \\
\hline & $V, F, 41 \mathrm{y}, 38 \mathrm{~m}$ & $\mathrm{SAH}$ & $15 \pm 1.6$ & $2 \pm 1$ & $4 \pm 2$ & $5 \pm 1$ & $2 \pm 3$ & 1 & $1 \pm 1$ & $1+2+3$ \\
\hline & $A, M, 53 \mathrm{y}, 35 \mathrm{~m}$ & WMH & $14 \pm 1.2$ & $3 \pm 1$ & $4 \pm 2$ & $2 \pm 2$ & $3 \pm 1$ & 1 & $1 \pm 1$ & $1+3$ \\
\hline & $V, M, 62 \mathrm{y}, 28 \mathrm{~m}$ & BG_h $h$ & $18 \pm 1.1$ & $3 \pm 1$ & $4 \pm 2$ & $4 \pm 2$ & $3 \pm 1$ & 1 & $3 \pm 1$ & \\
\hline & $T, F, 75$ y,13m & PO_ $h$ & $15 \pm 1.4$ & $3 \pm 1$ & $4 \pm 1$ & $4 \pm 2$ & $1 \pm 3$ & 1 & $2 \pm 1$ & $1+2+3$ \\
\hline mean $\pm \mathrm{SD}$ & $\begin{array}{l}10 T, 5 A, 4 V, 8 F, 11 M \\
55 \pm 12 \mathrm{y}, 18 \pm 11 \mathrm{~m}\end{array}$ & & $15 \pm 1$ & $3 \pm 1$ & $3 \pm 1$ & $4 \pm 1$ & $2 \pm 2$ & 1 & $2 \pm 1$ & \\
\hline \multirow{21}{*}{$\begin{array}{l}\text { UWS } \\
(n=21)\end{array}$} & $A, F, 62 \mathrm{y}, 19 \mathrm{~m}$ & WMH & $6 \pm 2$ & $2 \pm 1$ & $1 \pm 0.5$ & $1 \pm 0.5$ & $0.1 \pm 0.1$ & 0 & $2 \pm 0.5$ & \\
\hline & $A, F, 43 \mathrm{y}, 6 \mathrm{~m}$ & WMH & $6 \pm 2$ & $2 \pm 1$ & $1 \pm 1$ & $2 \pm 1$ & $0.1 \pm 0.1$ & 0 & $1 \pm 1$ & 1 \\
\hline & $T, M, 48 \mathrm{y}, 11 \mathrm{~m}$ & multiple_h $h$ & $7 \pm 3$ & $1 \pm 1$ & $1 \pm 0.5$ & $2 \pm 1$ & $1 \pm 1$ & 0 & $2 \pm 1$ & 3 \\
\hline & $T, F, 54 \mathrm{y}, 15 \mathrm{~m}$ & $\mathrm{DAI}+F \_h$ & $5 \pm 2$ & $1 \pm 1$ & $1 \pm 1$ & $1 \pm 0.5$ & $0.5 \pm 0.2$ & 0 & $1 \pm 1$ & $2+3$ \\
\hline & $T, M, 38 \mathrm{y}, 12 \mathrm{~m}$ & $\mathrm{DAI}+\mathrm{FP} \_h$ & $5 \pm 2$ & $1 \pm 1$ & $1 \pm 1$ & $1 \pm 1$ & $0.5 \pm 0.2$ & 0 & $1 \pm 1$ & 3 \\
\hline & $A, F, 38 \mathrm{y}, 6 \mathrm{~m}$ & WMH & $7 \pm 3$ & $1 \pm 0.2$ & $2 \pm 0.1$ & $1 \pm 0.5$ & $0.5 \pm 0.2$ & 0 & $2 \pm 0.5$ & 3 \\
\hline & $T, M, 45 \mathrm{y}, 6 \mathrm{~m}$ & DAI & $6 \pm 2$ & $1 \pm 1$ & $1 \pm 1$ & $1 \pm 1$ & $0.5 \pm 0.5$ & 0 & $2 \pm 0.5$ & $1+3$ \\
\hline & $A, F, 47 \mathrm{y}, 11 \mathrm{~m}$ & WMH & $6 \pm 2$ & $2 \pm 1$ & $1 \pm 0.5$ & $1 \pm 0.5$ & $0.1 \pm 0.2$ & 0 & $2 \pm 0.6$ & \\
\hline & $A, F, 42 \mathrm{y}, 13 \mathrm{~m}$ & WMH & $6 \pm 2$ & $2 \pm 1$ & $1 \pm 0.2$ & $2 \pm 1$ & $0.1 \pm 0.2$ & 0 & $1 \pm 2$ & $1+3$ \\
\hline & $T, M, 43 \mathrm{y}, 9 \mathrm{~m}$ & multiple_ $h$ & $6 \pm 2$ & $1 \pm 1$ & $1 \pm 0.6$ & $1 \pm 1$ & $1 \pm 2$ & 0 & $2 \pm 2$ & \\
\hline & $T, F, 46 \mathrm{y}, 12 \mathrm{~m}$ & $\mathrm{DAI}+\mathrm{F} \_h$ & $5 \pm 2$ & $1 \pm 1$ & $1 \pm 1$ & $1 \pm 0.6$ & $0.5 \pm 0.5$ & 0 & $1 \pm 1$ & 2 \\
\hline & $V, F, 68 \mathrm{y}, 19 \mathrm{~m}$ & FP_IS & $6 \pm 0.6$ & $1 \pm 1$ & $1 \pm 1$ & $2 \pm 1$ & $1 \pm 2$ & 0 & $1 \pm 2$ & \\
\hline & $A, M, 42 \mathrm{y}, 34 \mathrm{~m}$ & WMH & $5 \pm 0.4$ & $1 \pm 1$ & $1 \pm 1$ & $1 \pm 1$ & $1 \pm 2$ & 0 & $1 \pm 1$ & $1+3$ \\
\hline & $A, M, 63 \mathrm{y}, 19$ & WMH & $5 \pm 0.8$ & $2 \pm 1$ & $1 \pm 1$ & $1 \pm 1$ & $0 \pm 1$ & 0 & $1 \pm 1$ & $1+3$ \\
\hline & $V, F, 62 \mathrm{y}, 21 \mathrm{~m}$ & FTP_IS & $6 \pm 0.6$ & $2 \pm 1$ & $1 \pm 1$ & $1 \pm 1$ & $1 \pm 2$ & 0 & $1 \pm 2$ & 2 \\
\hline & $A, F, 52 \mathrm{y}, 19 \mathrm{~m}$ & WMH & $7 \pm 0.8$ & $1 \pm 1$ & $1 \pm 1$ & $2 \pm 1$ & $1 \pm 1$ & 0 & $2 \pm 2$ & 1 \\
\hline & $A, M, 58 \mathrm{y}, 28 \mathrm{~m}$ & WMH & $6 \pm 0.6$ & $1 \pm 1$ & $1 \pm 1$ & $1 \pm 1$ & $1 \pm 2$ & 0 & $2 \pm 1$ & \\
\hline & $V, F, 70 \mathrm{y}, 18 \mathrm{~m}$ & BG_h $h$ & $5 \pm 0.4$ & $1 \pm 1$ & $1 \pm 1$ & $1 \pm 1$ & $1 \pm 2$ & 0 & $1 \pm 1$ & 1 \\
\hline & $T, F, 60 \mathrm{y}, 14 \mathrm{~m}$ & $\mathrm{SAH}$ & $5 \pm 0.4$ & $1 \pm 1$ & $1 \pm 1$ & $1 \pm 1$ & $1 \pm 2$ & 0 & $1 \pm 2$ & $2+3$ \\
\hline & $\mathrm{T}, \mathrm{M}, 49 \mathrm{y}, 20 \mathrm{~m}$ & multiple_ $h$ & $4 \pm 0.5$ & $1 \pm 1$ & $1 \pm 1$ & $1 \pm 1$ & $0 \pm 1$ & 0 & $1 \pm 2$ & 1 \\
\hline & $V, F, 70$ y,39m & TP_IS & $5 \pm 0.8$ & $2 \pm 1$ & $1 \pm 1$ & $1 \pm 1$ & $0 \pm 1$ & 0 & $1 \pm 1$ & $1+2+3$ \\
\hline mean $\pm \mathrm{SD}$ & $\begin{array}{l}8 T, 9 A, 4 V, 12 F, 9 M \\
52 \pm 11 \mathrm{y}, 17 \pm 8 \mathrm{~m}\end{array}$ & & $6 \pm 1$ & $1 \pm 1$ & $1 \pm 1$ & $1 \pm 1$ & $1 \pm 1$ & 0 & $1 \pm 1$ & \\
\hline \multicolumn{11}{|l|}{ Group } \\
\hline comparison & & & $<0.001$ & $<0.001$ & $<0.001$ & $<0.001$ & $<0.001$ & & 0.1 & \\
\hline
\end{tabular}

Note: $L$-Dopa; 2 baclofen; 3 anti-epileptic drugs; $A$ anoxic; $b$ basal; BG basal ganglia; CRS-R baseline coma recovery scale-revised ( $A$ auditory, $V$ visual, $M$ motor, OM oromotor, $C$ communication, Ar arousal); DAI diffuse axonal injury; DoC disorder of consciousness; $F$ female; $F$ frontal; $h$ hemorrhagic lesion; IS ischemic stroke; $M$ male; MRI magnetic resonance imaging; NS nonsignificant; $O$ Occipital; $P$ parietal; SAH subarachnoid hemorrhage; $T$ temporal; $T$ traumatic; $V$ vascular; WMH white matter hyper-intensity. Patients who are only apparently UWS are marked in light gray. 
lack of motor-evoked potential (MEP) from right first dorsal interosseous muscle. The present study was approved by the Local Ethics Committee and written informed consent was obtained either from $\mathrm{HC}$ or the legal guardian of each patient.

\subsection{Experimental procedure}

We determined the effects on resting motor threshold, MEP amplitude, $\frac{40455}{45}$ short intracortical inhibition (SICI), and intracortical facilitation (ICF) strength (according to the Kujirai paired-pulse method ${ }^{(45}$ ), when applying the priming TDCS before the conditioning TDCS both to the left primary motor cortex, and when applying the priming TDCS to the left premotor cortex before the conditioning TDCS to primary motor cortex. These two brain areas were chosen to investigate primary motor cortex metaplasticity and the interregional metaplasticity between premotor and primary motor cortex (which reflects a functional connection) $\underline{46}$ Both anodal and cathodal TDCS were tested in all possible priming and conditioning combinations within primary motor cortex and between premotor and primary motor cortex. In addition, a priming
sham-TDCS preceded a conditioning cathodal TDCS in primary motor and premotor cortex. The time interval between the priming and conditioning TDCS was set as 3 min. 38 We did not test other primingconditioning intervals to avoid a highly fatiguing paradigm in such frail patients. Each subject followed all the protocols in different sessions, at every two days, while the order of sessions was kept random. Each parameter (MEP amplitude, SICI, and ICF strength) was tested before (PRE), and after 10 (T1), 30 (T2), and $60 \mathrm{~min}$ (T3) of the TDCS application. The experimental procedure with stimulation setup details is summarized in Fig. [1]

\subsection{Statistical analysis}

Student's $t$-tests were performed to determine whether the baseline parameters differed significantly. In all conditions, the normal distribution of the data was evaluated with the KolmogorovSmirnov test (all $p>0.2$ ).

The effects of TDCS (delivered on primary motor cortex and on premotor and primary motor cortex) on each electrophysiological parameter (MEP, SICI, and ICF) were measured by three-way

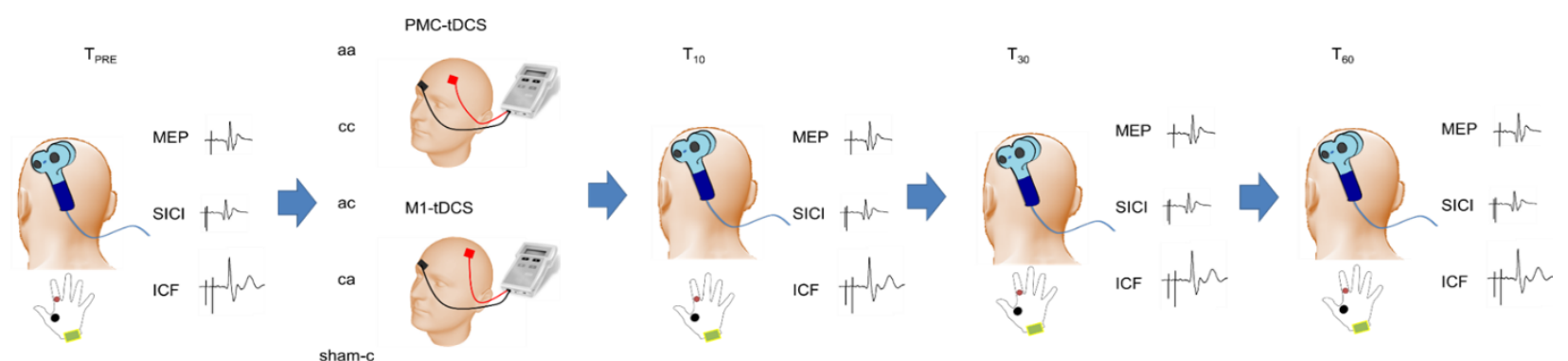

Fig. 1. Experimental design. TDCS was delivered through a BrainStim battery-driven electric stimulator (E.M.S., Bologna, Italy) wired to a pair of surface rubber electrodes $\left(35 \mathrm{~cm}^{2}\right)$ inside a saline-soaked sponge, and arranged according to the type of conditioning ( $c$ cathode, black electrode; $a$ anode, red electrode; PMC premotor cortex; M1 primary motor cortex). Currents were applied at $1 \mathrm{~mA}$ (current density $\sim 0.03 \mathrm{~mA} / \mathrm{cm}^{2}$ ) for $10 \mathrm{~min}$, with a $30 \mathrm{~s}$ ramping up/down period (this setup has been shown to be painless and strong enough to induce stable effects on motor cortex excitability). The other electrode was placed above the right orbit since this arrangement is known to result in significant excitability changes of the cortex. In the sham TDCS, the current was switched off after $30 \mathrm{~s}$. Motor cortex excitability was tested though single-pulse TMS delivered on the motor hot-spot of the right FDI by using a figure-of eight magnetic coil (diameter of one winding $9 \mathrm{~cm}$ ) wired to a Magstim 200 magnetic stimulator (Whiteland, Dyfed, UK). The coil was held tangentially to the skull, with the handle pointing backward and laterally at $45^{\circ}$ from the midline. The optimal coil position was defined as the site where TMS stimulation resulted consistently in the largest MEP. We recorded 10 MEPs induced by single TMS pulses set at a stimulator output intensity of $120 \%$ of resting motor threshold, which were intermingled with $15 \mathrm{SICI}$ and $15 \mathrm{ICF}$ interactions in a single trial, at a frequency of $0.2 \mathrm{~Hz}$. SICI and ICF were determined similarly to the Kujirai paired-pulse method. The intensity of the conditioning stimulus was set at a stimulator output intensity of $70 \%$ of resting motor threshold, and at an inter-stimulus interval of $2 \mathrm{~ms}$ and $12 \mathrm{~ms}$, respectively. Such intensities and intervals were kept constant throughout the experiment. Mean amplitude of the conditioned MEP was expressed as the percentage of unconditioned MEP amplitude and was taken as a measure of corticospinal excitability. 
repeated-measures ANOVA with priming (five levels: anodal-anodal, cathodal-cathodal, anodalcathodal, cathodal-anodal, and sham-cathodal) and time (four levels: $T_{\mathrm{PRE}}, T_{1}, T_{2}$, and $T_{3}$ ) as withinsubject factors, and group (three levels: HC, MCS, and UWS) as between-subject factor. A $p$-values $<0.05$ was considered significant. Depending on the significance of $F$-value, appropriate follow-up ANOVAs with the factors time and priming, and with the factors time, with post-hoc $t$-test (Bonferroni) were performed to explore the strength of main effects and the patterns of interaction between the experimental factors. In order to understand how large the differences between MCS and UWS were, we calculated the effect size Cohen's $d$. Given the relatively small sample size, we applied Hedge $g$ correction to the biased effect size estimate. $\eta^{2}$ and $\lambda$ were reported as well. Finally, the sensitivity and specificity of the electrophysiological measures employed to distinguish accurately between MCS and UWS were calculated by measuring the Area Under the Receiver Operating Characteristic Curve (AUC).

All data are given as mean or percent changes of the unconditioned MEP amplitude $\pm \mathrm{SD}$ (i.e. the baseline MEP without TDCS or paired-pulse TMS paradigm). A Spearman's correlation analysis was carried out to assess the total correlation between clinical-demographic and electrophysiological parameters in the patients with DoC. Withinand between-group correlations were computed when the total correlation was nonsignificant.

\section{Results}

\subsection{Baseline findings}

No significant difference in the clinical-demographic parameters between the DoC groups, except for the CRS-R score, was found (Table11). There was no significant difference between the resting motor threshold (52-60\% in each group) and MEP amplitude (0.42-0.71 $\mathrm{mV}$ in each group). In the HC group, SICI was low (MEP amplitude decrease), whereas ICF caused an increase in MEP amplitude (Figs. 2] and 31). On the contrary, individuals with DoC showed a tonically high cortical excitability, which was more evident in the patients with UWS than those with MCS, as shown by high SICI and ICF values (Figs. 20 and [3).

\subsection{Primary motor cortex metaplasticity}

All the subjects completed the experimental procedure without any side effect, beside a very mild, seldom tingling sensation beneath the cathode/anode electrode in the $\mathrm{HC}$ individuals was reported. ANOVA showed that that TDCS significantly influenced cortical excitability (time $\times$ group $\times$ priming $\times$ parameter $F_{(48,2976)}=4, p<0.001$; $\left.\lambda=193, \eta^{2}=0.9\right)$. In fact, we found a MEP amplitude and SICI strength modulation in HC and MCS individuals, while none of the UWS subjects (but three, n. 3, 16, and 19) showed excitability changes (Table 2). ICF was not influenced by any TDCS priming. In particular, we observed a significant increase in cortical excitability as shown by MEP amplitude increase when using cathodal-cathodal and cathodal-anodal TDCS in HC and MCS subjects and by SICI increase when using cathodalanodal TDCS in HC (Fig. 2). Conversely, cortical excitability decreased, as indexed by MEP amplitude decrease, when using anodal-anodal and anodalcathodal TDCS in HC, and by SICI decrease when using anodal-cathodal TDCS in $\mathrm{HC}$ and patients with MCS (Fig. 22). All these changes were detectable up to $T 2$ and were greater in magnitude in MCS than in $\mathrm{HC}$ individuals (Fig. 22), whereas the patients with UWS showed no changes. Nonetheless, only three patients with UWS (n. 3, 16, and 19) had a cortical facilitation/inhibition that was similar to that shown by the patients with MCS (Fig. 4). ICF did not show significant changes. Sham-cathodal TDCS in $\mathrm{HC}$ individuals induced a slight, nonsignificant SICI decrease without any effect on MEP and ICF magnitude, whereas it was ineffective in both DoC groups.

\subsection{Premotor cortex-primary motor cortex metaplasticity}

ANOVA showed that that TDCS significantly influenced cortical excitability (time $\times$ group $\times$ priming $\times$ parameter $F_{(48,2976)}=2.6, p<0.001 ; \lambda=123$, $\eta^{2}=0.9$ ). In fact, we found a MEP amplitude and SICI and ICF strength modulation in HC and MCS individuals, while none of the UWS subjects (but three, n. 3, 16, and 19) showed excitability changes (Table 31). In particular, we observed a significant increase in premotor-motor excitability in $\mathrm{HC}$ and 


\section{HC}

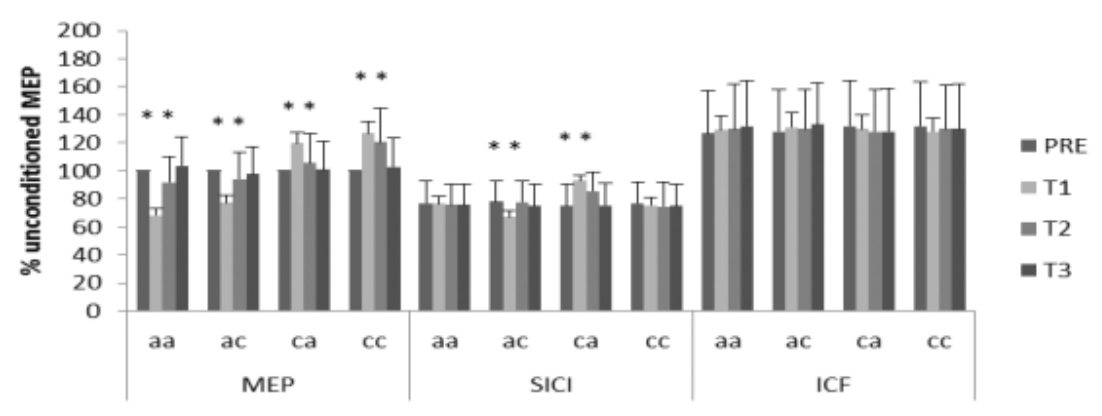

MCS

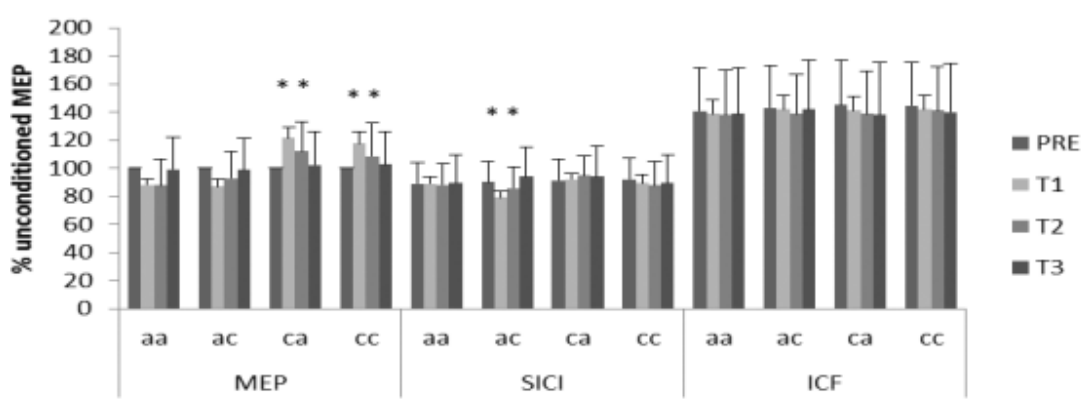

UWS

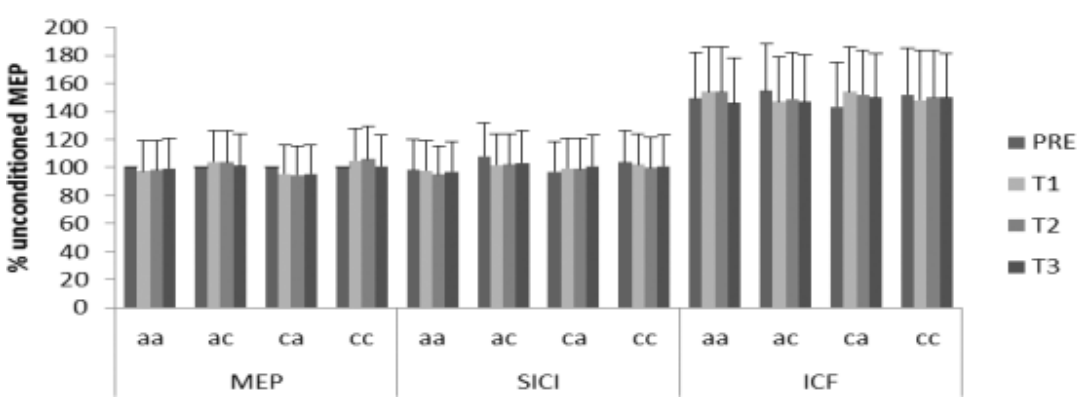

Fig. 2. Primary motor cortex TDCS effects onto MEP amplitude and SICI and ICF strength in the three groups of participants. Error bars refer to SD. * indicates a significant change at $T 1$ and $T 2$ as compared to PRE (baseline).

Note: HC healthy subjects, UWS Unresponsive Wakefulness Syndrome, MCS Minimally Conscious State, aa both-anodal, ac anodal-cathodal, $c a$ cathodal-anodal, $c c$ both-cathodal.

MCS when using cathodal-anodal TDCS as indexed by MEP amplitude, SICI, and ICF increase (Fig. 31). Conversely, premotor-motor excitability decreased when anodal-anodal TDCS was used, as shown by MEP amplitude and SICI decrease in HC and MCS (Table 3). All these changes were detectable up to $T 2$ and were greater in the patients with MCS than HC individuals, whereas patients with UWS showed no changes. Only three patients with UWS $(n .3,16$, and 19) had a premotor-motor facilitation/inhibition that was similar to the one shown by the individuals with MCS (Fig. 4). Sham-cathodal TDCS showed the same outcome; a slight effect on MEP amplitude was found in primary motor cortex metaplasticity paradigm without any effect on SICI and ICF.

\subsection{Clinical-electrophysiological correlations}

We found a significant total correlation between the CRS-R and the overall TDCS-induced SICI changes, 


\section{HC}
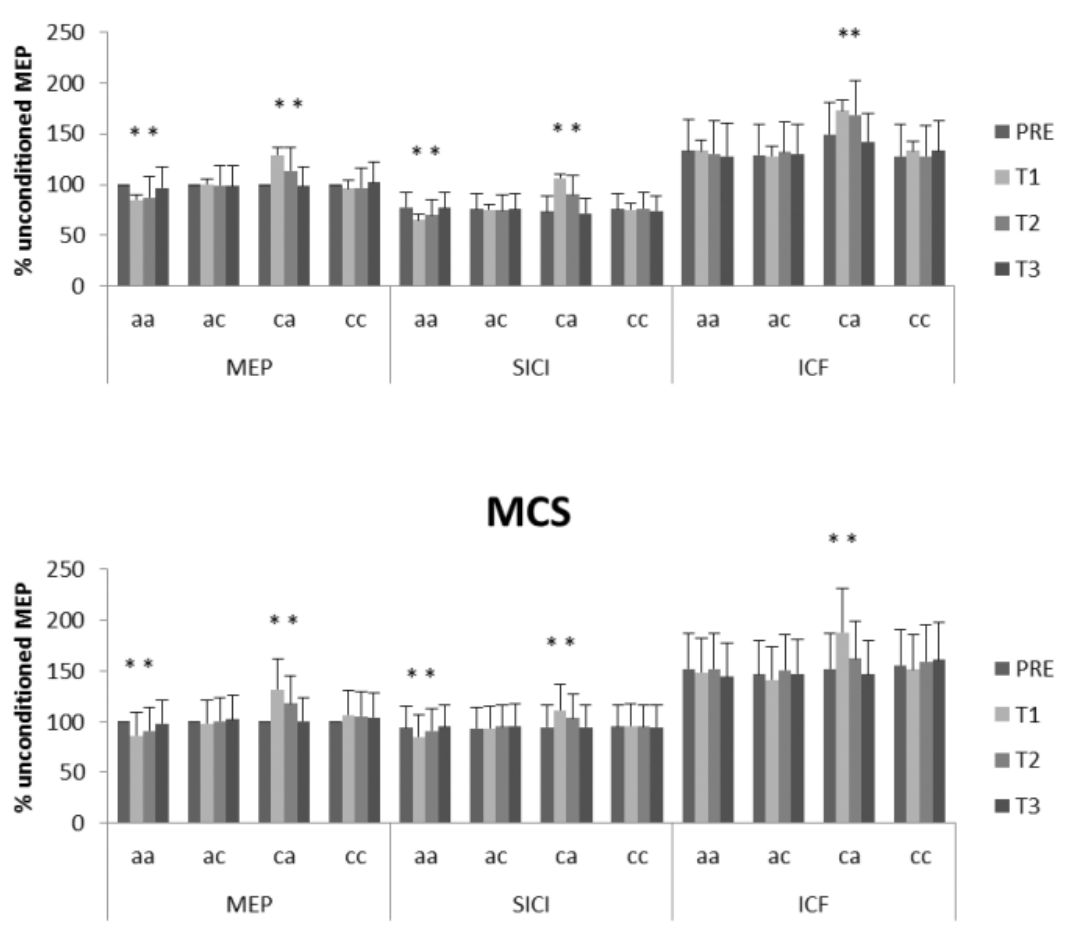

\section{UWS}

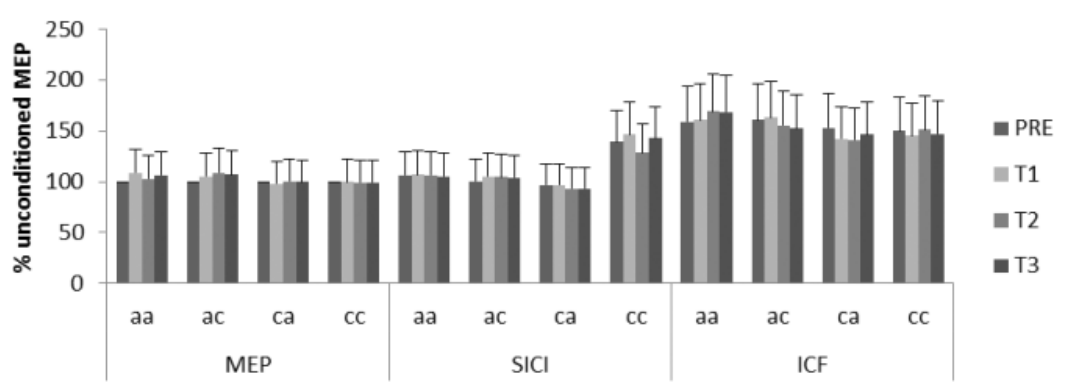

Fig. 3. Premotor cortex-primary motor cortex TDCS effects onto MEP amplitude and SICI and ICF strength in the three groups of participants. Error bars refer to SD. ${ }^{*}$ indicates a significant change at $T 1$ and $T 2$ as compared to PRE (baseline).

Note: HC healthy subjects, UWS Unresponsive Wakefulness Syndrome, MCS Minimally Conscious State, aa both-anodal, $a c$ anodal-cathodal, $c a$ cathodal-anodal, $c c$ both-cathodal.

i.e. the higher was the CRS-R score, the greater was the SICI magnitude modulation (i.e. the reduction of SICI at $T_{1}$, when the effect was stronger) $(r=$ $-0.941, p=0.001$ ) (Fig. 4(A)). Moreover, baseline SICI correlated with the CRS-R score, i.e. a higher CRS-R score was accompanied by a lower baseline SICI magnitude $(r=-0.884, p=0.001)$ (Fig. 4(B)). We found that the MEP amplitude modulation was higher at a higher CRS-R score $(r=0.894, p=0.001)$
(Fig. $4(\mathrm{C})$ ). The overall association between baseline SICI, MEP amplitude increase following TDCS, and CRS-R score are summarized in Fig. 5. In particular, we observed that the MEP amplitude increase was paralleled by stronger baseline SICI and higher CRSR scorings. Three patients with UWS ( $n .3,16$, and 19) showed a clinical-electrophysiological correlation that was much higher than that shown by the other patients with UWS. 
Table 2. ANOVA findings concerning TDCS over primary motor cortex. The signs in parentheses $(+/-)$ refer to the facilitatory or inhibitory effect of the TCDS polarity employed on the parameter, measured as $\%$ of the unconditioned MEP. Nonreported data (ICF, UWS group, sham-cathodal TDCS, and T3-TPRE interval) are nonsignificant.

\begin{tabular}{|c|c|c|c|c|}
\hline \multirow{2}{*}{$\begin{array}{l}\text { Time } \times \text { group } \\
\times \text { priming } F_{(24,1488)}\end{array}$} & \multirow{2}{*}{$\begin{array}{l}\text { Priming } \times \text { time } \\
\mathrm{HC}: F_{(12,288)} ; \\
\operatorname{MCS}: F_{(12,216)}\end{array}$} & \multirow{2}{*}{$\begin{array}{l}\text { Time } \mathrm{HC}: F_{(3,72)} \\
\text { MCS: } F_{(3,54)}\end{array}$} & \multicolumn{2}{|c|}{ Post-hoc $t$-test } \\
\hline & & & $T 1-T_{\mathrm{PRE}}$ & $T 2-T_{\mathrm{PRE}}$ \\
\hline \multirow[t]{6}{*}{$\begin{array}{l}\text { MEP } \\
F=7.7, p<0.001 \\
\lambda=184, \eta^{2}=0.9\end{array}$} & $\begin{array}{l}\mathrm{HC} \\
F=21, p<0.001 \\
\lambda=249, \eta^{2}=0.9\end{array}$ & $\begin{array}{l}(+) \mathrm{c}-\mathrm{c} \\
F=23, p<0.001 \\
\lambda=69, \eta^{2}=0.9\end{array}$ & $\begin{array}{l}p<0.001 \\
d=0.9\end{array}$ & $\begin{array}{l}p<0.001 \\
d=0.8\end{array}$ \\
\hline & & $\begin{array}{l}(+) \mathrm{c}-\mathrm{a} \\
F=9.3, p<0.001 \\
\lambda=28, \eta^{2}=0.9\end{array}$ & $\begin{array}{l}p<0.001 \\
d=0.8\end{array}$ & $\begin{array}{l}p=0.005 \\
d=0.6\end{array}$ \\
\hline & & $\begin{array}{l}(-) \mathrm{a}-\mathrm{a} \\
F=21, p<0.001 \\
\lambda=249, \eta^{2}=0.9\end{array}$ & $\begin{array}{l}p<0.001 \\
d=0.8\end{array}$ & $\begin{array}{l}p=0.008 \\
d=0.6\end{array}$ \\
\hline & & $\begin{array}{l}(-) \mathrm{a}-\mathrm{c} \\
F=9.3, p<0.001 \\
\lambda=28, \eta^{2}=0.9\end{array}$ & $\begin{array}{l}p<0.001 \\
d=0.9\end{array}$ & $\begin{array}{l}p<0.001 \\
d=0.8\end{array}$ \\
\hline & $\begin{array}{l}\text { MCS } \\
F=17, p<0.001 \\
\lambda=208, \eta^{2}=0.9\end{array}$ & $\begin{array}{l}(+) \mathrm{c}-\mathrm{c} \\
F=11, p<0.001 \\
\lambda=36, \eta^{2}=0.9\end{array}$ & $\begin{array}{l}p<0.001 \\
d=0.6\end{array}$ & $\begin{array}{l}p=0.001 \\
d=0.6\end{array}$ \\
\hline & & $\begin{array}{l}(+) \mathrm{c}-\mathrm{a} \\
F=14, p<0.001 \\
\lambda=43, \eta^{2}=0.9\end{array}$ & $\begin{array}{l}p=0.002 \\
d=0.6\end{array}$ & $\begin{array}{l}p=0.005 \\
d=0.5\end{array}$ \\
\hline \multirow[t]{3}{*}{$\begin{array}{l}\text { SICI } \\
F=9.1, p<0.001 \\
\lambda=219, \eta^{2}=0.9\end{array}$} & $\begin{array}{l}\mathrm{HC} \\
F=16, p<0.001 \\
\lambda=186, \eta^{2}=0.9\end{array}$ & $\begin{array}{l}(+) \mathrm{c}-\mathrm{a} \\
F=28, p<0.001 \\
\lambda=84, \eta^{2}=0.9\end{array}$ & $\begin{array}{l}p<0.001 \\
d=0.8\end{array}$ & $\begin{array}{l}p=0.003 \\
d=0.7\end{array}$ \\
\hline & & $\begin{array}{l}(-) \mathrm{a}-\mathrm{c} \\
F=34, p<0.001 \\
\lambda=104, \eta^{2}=0.9\end{array}$ & $\begin{array}{l}p<0.001 \\
d=0.8\end{array}$ & $\begin{array}{l}p=0.005 \\
d=0.5\end{array}$ \\
\hline & $\begin{array}{l}\text { MCS } \\
F=8, p<0.001 \\
\lambda=96, \eta^{2}=0.9\end{array}$ & $\begin{array}{l}(-) \mathrm{a}-\mathrm{c} \\
F=19, p<0.001 \\
\lambda=56, \eta^{2}=0.9\end{array}$ & $\begin{array}{l}p<0.001 \\
d=0.8\end{array}$ & $\begin{array}{l}p=0.007 \\
d=0.6\end{array}$ \\
\hline
\end{tabular}

Finally, receiver operating characteristic (ROC) analysis showed that the diagnostic accuracy of the overall SICI strength modulation was excellent (0.96) (Fig. 6(A)), i.e. the patients with MCS showed a TDCS-induced SICI strengthening, whereas the patients with UWS did not. In contrast, MEP amplitude (Fig. 6(B)) and ICF strength (Fig. 6(C)) modulations were poorly associated with DoC category (0.63 and 0.57 , respectively).

\section{Discussion}

To the best of our knowledge, this is the first study investigating metaplasticity in the patients with DoC. Our experimental paradigm was able to distinguish between MCS and UWS by inducing significant changes in SICI that strongly correlated with the CRS-R scoring.

\subsection{Putative neurophysiological mechanisms of TDCS-induced metaplasticity}

Healthy individuals showed some modulation of primary motor and premotor-motor excitability following the different types of TDCS consistent with homeostatic mechanisms of metaplasticity, i.e. the equal polarities yielded consistent 


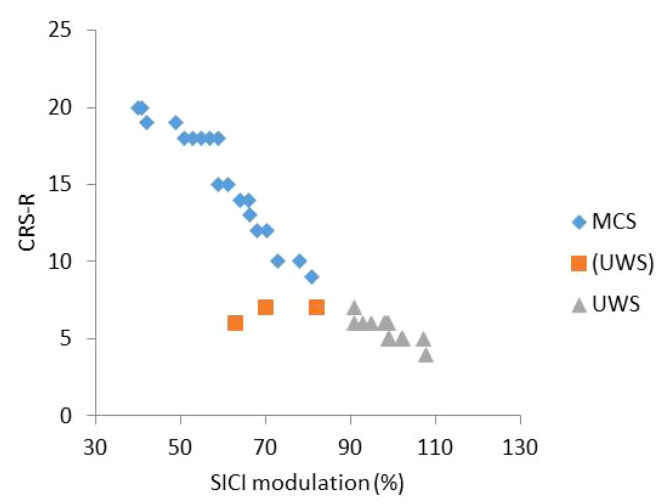

(a)

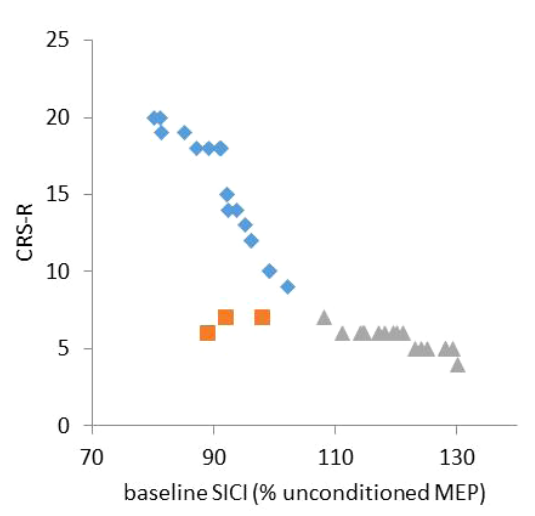

(b)

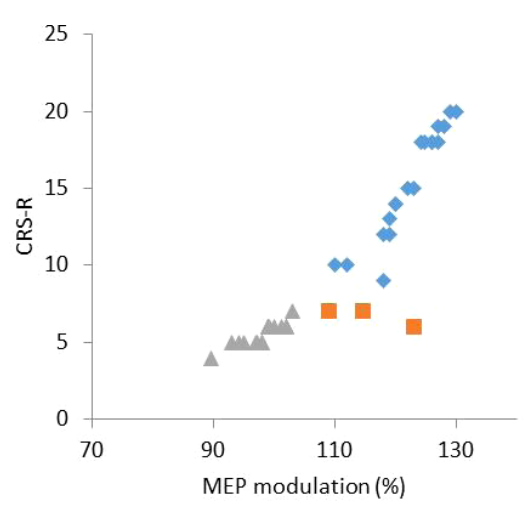

(c)

Fig. 4. The scatterplots of the significant correlations between CRS-R and electrophysiological findings (overall TDCS-induced modulation of SICI and MEP magnitude, baseline SICI strength). $\Delta$ indicate patients with UWS, $\checkmark$ those with MCS, . those with the supposed Functional Locked-In Syndrome.

facilitatory or inhibitory after-effects, whereas the opposite polarities induced diametrically opposed effects as compared to the same stand-alone

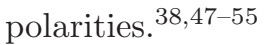

The underlying cellular and molecular mechanisms supporting these metaplasticity models are partially known. TDCS-induced metaplasticity could depend on cellular mechanisms within the pyramidal neurons 56 at least when using the same TDCS polarity (i.e. cathodal-cathodal and anodal-anodal). In fact, the measurability of TDCS after-effects depends on the paired-pulse interval tested $\lcm{3875758}$ In addition, the paired-pulse TMS interval we used could test glutamatergic and $\gamma$-aminobutyric acidergic neurons that are different from those involved in the homeostatic plasticity

The finding agrees with the previous experimental models highlighting the role of the inhibitory synapses concerning metaplasticity regulation.435459 64 The discrepancy between the homogeneous and non-homogeneous TDCS polarities concerning SICI may depend on a different entrainment of the inhibitory neuronal networks surrounding pyramidal cells (probably generating late $I$-waves), $\frac{64}{6}$ depending on the TDCS polarities and intervals employed $\underline{23655} \underline{68}$ Indeed, short-lasting TDCS protocols may target $L$-type voltage-gated $\mathrm{Ca}^{2+}$ channels $\sqrt{6769}$ that regulate the magnitude of LTP/LTD strength (i.e. the high levels of postsynaptic $\mathrm{Ca}^{2+}$ favor LTP, whereas the low levels favor LTD; thereafter, preceding high levels of postsynaptic $\mathrm{Ca}^{2+}$ favor LTD, whereas low levels favor LTP) ${ }^{70171}$ Moreover, some inhibitory populations can be shaped more quickly by the opposite TDCS polarities, whereas other populations may not show sufficient response depending on the smallness of threshold as compared to pyramidal neurons $43[64$ and the previous synaptic activity $\stackrel{38}{ }$ MEP amplitude showed less evident TDCS-induced changes, as compared to SICI and ICF. However, MEP is a complex measure of corticospinal excitability and is influenced by either cortical or subcortical circuits projecting into the corticospinal motor neurons. ${ }^{72,74}$ Moreover, subtle homeostatic changes may have an effect size that remains within the noise level of normal fluctuations in MEP amplitude $\stackrel{3875}{ }$ Further, ICF is barely changed by primary motor cortex metaplasticity protocols. Methodological factors may avoid an ICF modulation, which requires posteroanterior current flow (while inhibition can be elicited regardless of the direction of current flow) $\underline{63}$ In fact, the premotor-primary motor cortex TDCS induces rather clear ICF 
Table 3. ANOVA findings concerning TDCS over premotor cortex. The signs in parentheses $(+/-)$ refer to the facilitatory or inhibitory effect of the TCDS polarity employed on the parameter, measured as \% on the unconditioned MEP. Non-reported data (UWS group, sham-cathodal TDCS, and T3-TPRE interval) are nonsignificant.

\begin{tabular}{|c|c|c|c|c|}
\hline \multirow{2}{*}{$\begin{array}{l}\text { Time } \times \text { group } \\
\times \text { priming } F_{(24,1488)}\end{array}$} & \multirow{2}{*}{$\begin{array}{l}\text { Priming } \times \text { time } \\
\text { HC: } F_{(12,288)} ; \\
\operatorname{MCS}: F_{(12,216)}\end{array}$} & \multirow{2}{*}{$\begin{array}{l}\text { Time } \mathrm{HC}: F_{(3,72)} \\
\text { MCS: } F_{(3,54)}\end{array}$} & \multicolumn{2}{|c|}{ Post-hoc $t$-test } \\
\hline & & & $T 1-T_{\mathrm{PRE}}$ & $T 2-T_{\mathrm{PRE}}$ \\
\hline \multirow{6}{*}{$\begin{array}{l}\mathrm{MEP} \\
F=5.4, p<0.001 \\
\lambda=129, \eta^{2}=0.9\end{array}$} & \multirow{3}{*}{$\begin{array}{l}\mathrm{HC} \\
F=10, p<0.001 \\
\lambda=120, \eta^{2}=0.9\end{array}$} & $(+) \mathrm{c}-\mathrm{a}$ & $p<0.001$ & $p<0.001$ \\
\hline & & $\begin{array}{l}F=45, p<0.001 \\
\lambda=136, \eta^{2}=0.9\end{array}$ & $d=0.8$ & $d=0.8$ \\
\hline & & $\begin{array}{l}(-) \mathrm{a}-\mathrm{a} \\
F=4.1, p=0.009 \\
\lambda=12, \eta^{2}=0.8\end{array}$ & $\begin{array}{l}p<0.001 \\
d=0.8\end{array}$ & $\begin{array}{l}p<0.001 \\
d=0.7\end{array}$ \\
\hline & \multirow{3}{*}{$\begin{array}{l}\text { MCS } \\
F=2.6, p=0.003 \\
\lambda=31, \eta^{2}=0.8\end{array}$} & $(+) \mathrm{c}-\mathrm{a}$ & $p<0.001$ & $p<0.001$ \\
\hline & & $\begin{array}{l}F=17, p<0.001 \\
\lambda=52, \eta^{2}=0.9\end{array}$ & $d=0.9$ & $d=0.8$ \\
\hline & & $\begin{array}{l}(-) \mathrm{a}-\mathrm{a} \\
F=7.8, p<0.001 \\
\lambda=23, \eta^{2}=0.9\end{array}$ & $\begin{array}{l}p<0.001 \\
d=0.9\end{array}$ & $\begin{array}{l}p<0.001 \\
d=0.8\end{array}$ \\
\hline \multirow{4}{*}{$\begin{array}{l}\text { SICI } \\
F=4.8, p<0.001 \\
\lambda=115, \eta^{2}=0.9\end{array}$} & \multirow{3}{*}{$\begin{array}{l}\mathrm{HC} \\
F=21, p<0.001 \\
\lambda=248, \eta^{2}=0.9\end{array}$} & $(+) \mathrm{c}-\mathrm{a}$ & $p<0.001$ & $p<0.001$ \\
\hline & & $\begin{array}{l}F=92, p<0.001 \\
\lambda=278, \eta^{2}=0.9\end{array}$ & $d=0.9$ & $d=0.9$ \\
\hline & & $\begin{array}{l}(-) \mathrm{a}-\mathrm{a} \\
F=2.7, p=0.04 \\
\lambda=8.1, \eta^{2}=0.6\end{array}$ & $\begin{array}{l}p<0.001 \\
d=0.8\end{array}$ & $\begin{array}{l}p=0.01 \\
d=0 .+\end{array}$ \\
\hline & $\begin{array}{l}\text { MCS } \\
F=8, p<0.001 \\
\lambda=96, \eta^{2}=0.9\end{array}$ & $\begin{array}{l}(-) \mathrm{a}-\mathrm{a} \\
F=16, p<0.001 \\
\lambda=47, \eta^{2}=0.9\end{array}$ & $\begin{array}{l}p<0.001 \\
d=0.9\end{array}$ & $\begin{array}{l}p=0.001 \\
d=0.7\end{array}$ \\
\hline \multirow[t]{2}{*}{$\begin{array}{l}\mathrm{ICF} \\
F=4.5, p<0.001 \\
\lambda=113, \eta^{2}=0.9\end{array}$} & $\begin{array}{l}\mathrm{HC} \\
F=12, p<0.001 \\
\lambda=140, \eta^{2}=0.9\end{array}$ & $\begin{array}{l}(+) \mathrm{c}-\mathrm{a} \\
F=46, p<0.001 \\
\lambda=138, \eta^{2}=0.9\end{array}$ & $\begin{array}{l}p<0.001 \\
d=0.9\end{array}$ & $\begin{array}{l}p<0.001 \\
d=0.9\end{array}$ \\
\hline & $\begin{array}{l}\text { MCS } \\
F=5.7, p<0.001 \\
\lambda=68, \eta^{2}=0.9\end{array}$ & $\begin{array}{l}(+) \mathrm{c}-\mathrm{a} \\
F=19, p<0.001 \\
\lambda=60, \eta^{2}=0.9\end{array}$ & $\begin{array}{l}p<0.001 \\
d=0.9\end{array}$ & $\begin{array}{l}p<0.001 \\
d=0.9\end{array}$ \\
\hline
\end{tabular}

changes ${ }^{76} 78$ Therefore, other homeostatic plasticity mechanisms might contribute to TDCS-induced metaplasticity $[64$ which should be addressed in future studies.

\subsection{Metaplasticity in patients with DoC}

Metaplasticity was largely abnormal in patients with DoC. Indeed, both DoC groups showed a tonically high cortical excitability as compared to $\mathrm{HC}$ individuals, but the patients with MCS showed a greater TDCS-induced modulability of SICI (and partially of ICF and MEP) than UWS individuals did (except patients n. 3, 16, and 19). In particular, the degree of metaplasticity abnormality, measured through the baseline SICI and TDCSinduced SICI modulation, was inversely correlated with the CRS-R scoring. AUC analysis confirmed that only SICI well distinguished between the DoC groups. Such data confirm the important role of the degree of functional impairment of cortical, and even thalamo-cortical, inhibitory circuitries concerning the awareness impairment estimated by the CRS-R, 26.28179 84 independently from the integrity of corticospinal tract (as reflected by the mild changes of MEP amplitude). $\frac{85186}{}$ Therefore, the assessment of the brain responses to TDCS-based 


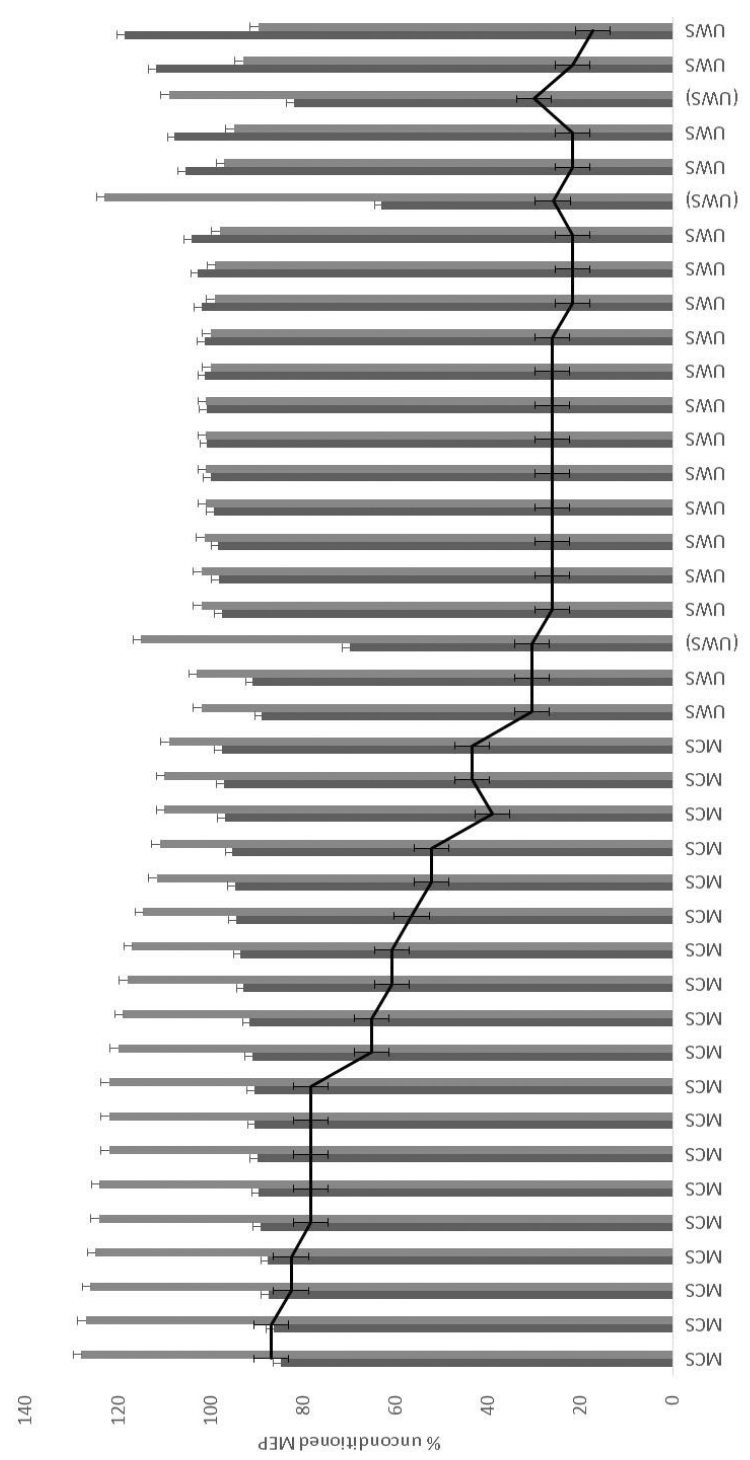

Fig. 5. Association between baseline SICI, MEP amplitude modulation following TDCS over primary motor cortex, and CRS-R scoring. Some among the patients with UWS (those in parentheses) showed electrophysiological values largely outside those shown by the other patients with UWS.

Note: UWS Unresponsive Wakefulness Syndrome, MCS Minimally Conscious State, $a a$ both-anodal, $a c$ anodalcathodal, $c a$ cathodal-anodal, $c c$ both-cathodal.

metaplasticity protocols may indicate the amount of residual plasticity that correlates with the degree of awareness, thus differentiating patients with DoC.

Cortical disexcitability in the patients with DoC may depend on a decoupled activity of facilitatory ( $N$-methyl- $D$-aspartate) and inhibitory $(\gamma$-aminobutyric acid) interneurons following brain injury,$\widehat{87888}$ where the former can facilitate the deterioration of the latter, in keeping with the severity of brain damage. This could be the reason why ICF was less modulable and so had a marginal role in distinguishing patients with DoC. It has been proposed that the drop in inhibitory circuits offers more favorable conditions for the development of restorative plastic changes that facilitate the restoration of the impaired networks ${ }^{33334}$ This cortical facilitation is a consequence of cortical deafferentation due to the thalamo-cortical projection deterioration, and is also influenced by other factors influencing those neurotransmitters that are important for metaplasticity regulation (including the threshold for postischemic LTP, ${ }^{[89}$ nitric oxide signaling, ${ }^{90}$ the ignition of delayed apoptosis-like neuronal death process,, 91 and the release of stress hormones 13 -16).

Cortical disexcitability in patients with DoC was further demonstrated by the lack of effects of single cathodal TDCS (in the sham protocol), which instead affected SICI in HC as formerly shown!92[93 At the same time, the sham protocol would rule out a possible causal effect of double TDCS protocols on cortical excitability.

Three patients with UWS (n. 3, 16, and 19) showed residual TDCS-induced responses that were similar to those shown in patients with MCS. However, such patients with UWS showed a CRS$\mathrm{R}$ score that was the same of the other patients with UWS, who although showed nonsignificant TDCS-induced brain responses. A similar condition may suggest a diagnosis of Functional LockedIn Syndrome, which is characterized by a residual brain connectivity (suggesting awareness preservation) despite a severe behavioral impairment. 94 This dissociation probably depends on a severe deterioration of sensory-motor circuitries ${ }^{30}$ However, this finding was interpreted cautiously as this TDCS after-effect was noted only in one individual.

\subsection{Limitation and conclusions}

One could concern that the relatively small sample size limits the significance of multiple comparisons made (as the required sample size increases linearly with the logarithm of the number of comparisons made). However, the required sample size for detecting a between-group difference between TDCS 


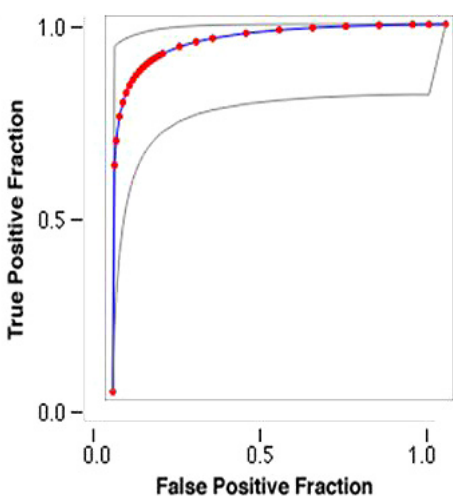

(a)

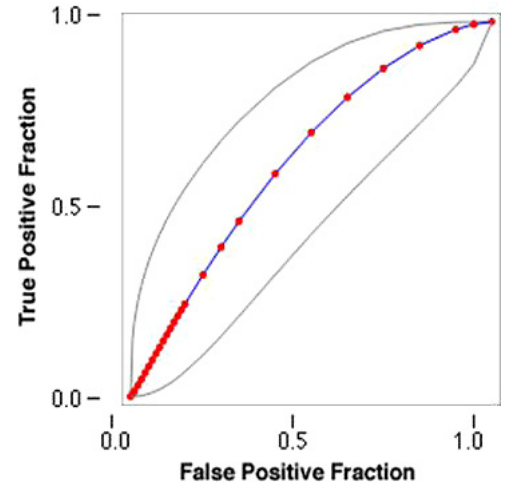

(b)

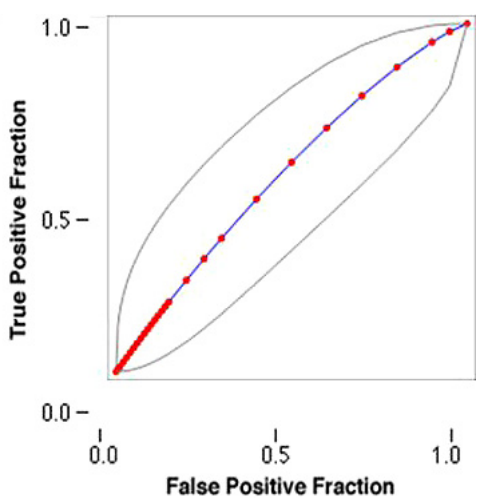

(c)

Fig. 6. The power of SICI, MEP, and ICF modulation in differentiating patients with DoC is shown by the AUC of the ROC in panels $(A)-(C)$, respectively.

after-effects using the typical conventions of $80 \%$ power, a two-tailed alpha of 0.05 , and a putative metaplasticity effect size of approximately 0.40 (in keeping with the available literature data on TDCS in patients with DoC) 108 should be of at least 35 subjects, $106 \mid 107$ which is satisfied by our sample. Further, the differences between the patients with DoC were statistically significant, as also shown by the effect size data indicating a big effect of TDCS on SICI, above all. Finally, to recruit a sufficient number of patients with chronic DoC in a single center study is challenging, due to the unfortunately high negative outcome and the thorny selection of patients based on the inclusion criteria required by the typology of the study.

We can only speculate on the influence of TDCS on thalamo-cortical connectivity in patients with DoC, given that we tested only a small slice of brain connectivity, i.e. between the premotor and motor cortices. However, the frontal lobe TDCS is known to modulate thalamo-cortical connectivity through multiple fronto-striatal connections, $\frac{108 / 109}{10}$ beyond the facilitatory projections from premotor to motor cortex, 110 as suggested by the ICF increase during premotor-motor TDCS. The premotor-motor excitability was clearly deteriorated in the patients with DoC in correlation with the CRS-R score. This further confirms that a connectivity breakdown within distinct cortical areas accounts for the loss of consciousness in patients with DoC, 111 115 and suggests that the connectivity impairment between premotor and motor cortices is significant to cause motor output deterioration, even when a patient shows a partially preserved whole brain connectivity $29|30| 116$

One could argue that the lack of conditioning after-effects in patients with DoC may depend on the fact that TDCS fails to recruit the SICI networks, $117 \mid 118$ rather than on a low amount of plasticity. However, the magnitude of TDCS after-effects depended on baseline SICI values; therefore, if a patient has a sufficient SICI, we may assume that the lack of response to TDCS may properly indicate a reduced plasticity, thus differentiating patients with DoC.

Given the small number of available studies dealing with TDCS in patients with DoC, 100 we can only try to quantify the relevance of our method in comparison with the other state-of-the-art methods. Our data indicate that metaplasticity is valuable in differentiating patients with DoC. Larger cohort studies comparing different sites of stimulation (since some patients may benefit from TDCS targeting different cortical areas, based on their brain lesions) are therefore needed to confirm the possible superiority of one specific approach.

In conclusion, our promising data suggest that the assessment of metaplasticity may quantify the residual plasticity properties in patients with DoC, which correlate with the degree of awareness. Therefore, metaplasticity assessment could be used to corroborate (or not) clinical DoC diagnosis, potentially reducing the still high misdiagnosis rate.32 Moreover, we have to acknowledge the relevance of metaplasticity in Bio-Inspired Machine Learning, which could usefully be employed in the management 
of patients with DoC $119 \sqrt[121]{121}$ Finally, metaplasticity assessment in patients with DoC may identify the subjects who could benefit from neuromodulation protocols, and help the clinicians implementing more personalized neurorehabilitative training for such a very frail and vulnerable group of patients.

\section{References}

1. G. G. Turrigiano and S. B. Nelson, Homeostatic plasticity in the developing nervous system, Nat. Rev. Neurosci. 5(2) (2004) 97-107.

2. W. C. Abraham, Metaplasticity: Tuning synapses and networks for plasticity, Nat. Rev. Neurosci. 9(5) (2008) 387.

3. Y. Y. Huang, A. Colino, D. K. Selig and R. C. Malenka, The influence of prior synaptic activity on the induction of long-term potentiation, Science 255 (1992) 730-733.

4. S. R. Hulme, O. D. Jones and W. C. Abraham, Emerging roles of metaplasticity in behaviour and disease, Trends Neurosci 36(6) (2013) 353-362.

5. T. H. Murphy and D. Corbett, Plasticity during stroke recovery: From synapse to behaviour, Nat. Rev. Neurosci. 10 (2009) 861-872.

6. E. L. Bienenstock, L. N. Cooper and P. W. Munro, Theory for the development of neuron selectivity: Orientation specificity and binocular interaction in visual cortex, J. Neurosci. 2 (1982) 32-48.

7. W. Abraham and M. F. Bear, Metaplasticity: The plasticity of synaptic plasticity, Trends Neurosci. 19 (1996) 126-130.

8. A. X. Yee, Y. T. Hsu and L. Chen, A metaplasticity view of the interaction between homeostatic and Hebbian plasticity, Philos. Trans. R. Soc. Lond. B Biol. Sci. 372 (2017) (1715) 20160155.

9. I. Delvendahl, N. H. Jung, F. Mainberger, N. G. Kuhnke, M. Cronjaeger and V. Mall, Occlusion of bidirectional plasticity by preceding low-frequency stimulation in the human motor cortex, Clin. Neurophysiol. 121(4) (2010) 594-602.

10. H. R. Siebner, A primer on priming the human motor cortex, Clin. Neurophysiol. 121(4) (2010) 461-463.

11. G. Turrigiano, Homeostatic synaptic plasticity: local and global mechanisms for stabilizing neuronal function, Cold Spring Harb. Perspect Biol. 4(1) (2012) a005736.

12. G. G. Turrigiano, The self-tuning neuron: Synaptic scaling of excitatory synapses, Cell 135 (2008) 422435.

13. J. J. Kim and K. S. Yoon, Stress: Metaplastic effects in the hippocampus, Trends Neurosci. 21(12) (1998) 505-509.

14. T. Takahashi, T. Kimoto, N. Tanabe, T. A. Hattori, N. Yasumatsu and S. Kawato, Corticosterone acutely prolonged N-methyl-d-aspartate receptormediated $\mathrm{Ca} 2+$ elevation in cultured rat hippocampal neurons, J. Neurochem. 83(6) (2002) 14411451.

15. G. Whitehead, J. Jo, E. L. Hogg, T. Piers, D. H. Kim, G. Seaton, H. Seok, G. Bru-Mercier, G. H. Son, P. Regan, L. Hildebrandt, E. Waite, B. C. Kim, T. L. Kerrigan, K. Kim, D. J. Whitcomb, G. L Collingridge, S. L. Lightman and K. Cho, Acute stress causes rapid synaptic insertion of $\mathrm{Ca}^{2+}$-permeable AMPA receptors to facilitate long-term potentiation in the hippocampus, Brain 136(12) (2013) 3753-3765.

16. T. Takahashi, A neuroeconomic theory of bidirectional synaptic plasticity and addiction, Med. Hypotheses 75(4) (2010) 356-358.

17. S. Sajikumar, Synaptic Tagging and Capture: From Synapses to Behavior (Springer, New York, 2015).

18. M. W. Debono Leonardo, From Perception to Consciousness: An epistemic vision of evolutionary processes, MIT Press 37(3) (2004) 243-248.

19. P. Yger and M. Gilson, Models of Metaplasticity: A Review of Concepts, Front Comput. Neurosci. 9 (2015) 138.

20. D. Morrison, Metaplasticity: A new frontier in the neural representation of memory, $U B C$ Undergrad. J. Psychol. 1 (2012) 1-12.

21. C. Roth-Alpermann, R. G. Morris, M. Korte and T. Bonhoeffer, Homeostatic shutdown of long-term potentiation in the adult hippocampus, Proc. Natl. Acad. Sci. USA 103 (2006) 11039-11044.

22. H. Wang and J. J. Wagner, Priming-induced shift in synaptic plasticity in the rat hippocampus, $J$. Neurophysiol. 82 (1999) 2024-2028.

23. D. Liebetanz, M. A. Nitsche, F. Tergau and W. Paulus, Pharmacological approach to the mechanisms of transcranial DC-stimulation-induced aftereffects of human motor cortex excitability, Brain 125(10) (2002) 2238-2247.

24. A. Demirtas-Tatlidede, A. M. Vahabzadeh-Hagh, M. Bernabeu, J. M. Tormos and A. PascualLeone, Noninvasive brain stimulation in traumatic brain injury, J. Head Trauma Rehabil. 27 (2012) 274-292.

25. A. J. Woods, A. Antal, M. Bikson, P. S. Boggio, A. R. Brunoni, P. Celnik et al., A technical guide to TDCS , and related non-invasive brain stimulation tools, Clin. Neurophysiol. 127(2) (2016) 1031-1048

26. S. Bagnato, C. Boccagni, A. Sant'Angelo, C. Prestandrea, S. Rizzo and G. Galardi, Patients in a vegetative state following traumatic brain injury display a reduced intracortical modulation, Clin. Neurophysiol. 123(10) (2012) 1937-1941.

27. N. Lapitskaya, O. Gosseries, V. De Pasqua, A. R. Pedersen, J. F. Nielsen, A. M. de Noordhout and S. Laureys, Abnormal corticospinal excitability in patients with disorders of consciousness, Brain Stimul. 6(4) (2013) 590-597. 
28. S. Bagnato, C. Boccagni, A. Sant'angelo, A. A. Fingelkurts, A. A. Fingelkurts and G. Galardi, Emerging from an unresponsive wakefulness syndrome: Brain plasticity has to cross a threshold level, Neurosci. Biobehav. Rev. 37(10) (2013) 27212736 .

29. A. Naro, M. Russo, A. Leo, P. Bramanti, A. Quartarone and R. S. Calabrò, A single session of repetitive transcranial magnetic stimulation over the dorsolateral prefrontal cortex in patients with unresponsive wakefulness syndrome: Preliminary results, Neurorehabil. Neural Repair 29(7) (2015) $603-613$.

30. A. Naro, A. Leo, A. Buda, A. Manuli, A. Bramanti, P. Bramanti and R. S. Calabrò, Unravelling motor networks in patients with chronic disorders of consciousness: A promising minimally invasive approach, Brain Res. 1646 (2015) 262-268.

31. O. Gosseries, A. Thibaut, M. Boly , M. Rosanova, M. Massimini and S. Laureys, Assessing consciousness in coma and related states using transcranial magnetic stimulation combined with electroencephalography, Ann. Fr. Anesth. Reanim 33(2) (2014) 65-71.

32. C. Schnakers, A. Vanhaudenhuyse, J. Giacino, M. Ventura, M. Boly, S. Majerus and S. Laureys, Diagnostic accuracy of the vegetative and minimally conscious state: Clinical consensus versus standardized neurobehavioral assessment, BMC Neurol. 9 (2009) 35.

33. J. L. Chen, W. C. Lin, J. W. Cha, P. T. So, Y. Kubota and E. Nedivi, Structural basis for the role of inhibition in facilitating adult brain plasticity, Nature Neurosci. 14 (2011) 587-594.

34. F. Pistoia, E. Mura, S. Govoni, M. Fini and M. Sarà, Awakenings and awareness recovery in disorders of consciousness: Is there a role for drugs? CNS Drugs 24 (2010) 625-638.

35. S. Li, A. L. Zaninotto, I. S. Neville, W. S. Paiva, D. Nunn and F. Fregni, Clinical utility of brain stimulation modalities following traumatic brain injury: Current evidence, Neuropsychiatr. Dis. Treat. 11 (2015) 1573-1586.

36. J. T. Giacino, J. Kalmar and K. Whyte, The JFK Coma Recovery Scale-Revised, measurement characteristics and diagnostic utility, Arch. Phys. Med. Rehabil. 85 (2004) 2020-2029.

37. The multi-society task force on PVS, Medical aspects of the persistent vegetative state, N. Engl. J. Med. 330 (1994) 1499-508.

38. K. Fricke, A. A. Seeber, N. Thirugnanasambandam, W. Paulus, M. A. Nitsche and J. C. Rothwell, Time course of the induction of homeostatic plasticity generated by repeated transcranial direct current stimulation of the human motor cortex, J. Neurophysiol. 105(3) (2011) 1141-1149.
39. M. A. Nitsche and W. Paulus, Excitability changes induced in the human motor cortex by weak transcranial direct current stimulation, J. Physiol. $\mathbf{5 2 7}$ (2000) 633-639.

40. F. Awiszus, H. Feistner, D. Urbach and H. Bostock, Characterisation of paired-pulse transcranial magnetic stimulation conditions yielding intracortical inhibition or I-wave facilitation using a thresholdhunting paradigm, Exp. Brain Res. 129 (1999) 317324.

41. R. Chen and R. Garg, Facilitatory I wave interaction in proximal arm and lower limb muscle representations of the human motor cortex, J. Neurophysiol. 83 (2000) 1426-1434.

42. R. Chen, A. Tam, C. Bütefisch, B. Corwell, U. Ziemann, J. C. Rothwell and L. G. Cohen, Intracortical inhibition and facilitation in different representations of the human motor cortex, J. Neurophysiol. 80 (1998) 2870-2881.

43. T. Kujirai, M. D. Caramia, J. C. Rothwell, B. L. Day, P. D. Thompson, A. Ferbert et al., Corticocortical inhibition in human motor cortex, J. Physiol. 471 (1993) 501-519.

44. A. Schurr, Energy metabolism, stress hormones and neural recovery from cerebral ischemia/hypoxia, Neurochem. Int. 41(1) (2002) 1-8.

45. P. M. Rossini, D. Burke, R. Chen, L. G. Cohen, Z. Daskalakis, R. Di Iorio, V. Di Lazzaro, F. Ferreri, P. B. Fitzgerald, M. S. George, M. Hallett, J. P. Lefaucheur, B. Langguth, H. Matsumoto, C Miniussi, M. A. Nitsche, A. Pascual-Leone, W. Paulus, S. Rossi, J. C. Rothwell, H. R. Siebner, Y. Ugawa, V. Walsh and U. Ziemann, Non-invasive electrical and magnetic stimulation of the brain, spinal cord, roots and peripheral nerves: Basic principles and procedures for routine clinical and research application. An updated report from an I.F.C.N. Committee, Clin. Neurophysiol. 126(6) (2015) 1071-1107.

46. R. C. Gerkin, D. W. Nauen, F. Xu and G. Q. Bi, Homeostatic regulation of spontaneous and evoked synaptic transmission in two steps, Mol. Brain 6 (2013) 38.

47. M. C. Ridding, J. L. Taylor and J. C. Rothwell, The effect of voluntary contraction on cortico-cortical inhibition in human motor cortex, J. Physiol. 487 (1995) 541-548.

48. T. D. Sanger, R. R. Garg and R. Chen, Interactions between two different inhibitory systems in the human motor cortex, J. Physiol. 530(2) (2001) 307-317.

49. V. Di Lazzaro, F. Pilato, E. Saturno, et al., Thetaburst repetitive transcranial magnetic stimulation suppresses specific excitatory circuits in the human motor cortex, J. Physiol. 565(3) (2005) 945950. 
50. M. Hamada, Y. Terao, R. Hanajima, et al., Bidirectional long-term motor cortical plasticity and metaplasticity induced by quadripulse transcranial magnetic stimulation, J. Physiol. 586 (2008) $3927-$ 3947.

51. Y. Z. Huang, M. J. Edwards, E. Rounis et al., Theta burst stimulation of the human motor cortex, Neuron 45 (2005) 201-206.

52. M. B. Iyer, N. Schleper and E. M. Wassermann, Priming stimulation enhances the depressant effect of low-frequency repetitive transcranial magnetic stimulation, J. Neurosci. 23 (2003) 10867-10872.

53. N. Lang, H. R. Siebner, D. Ernst et al., Preconditioning with transcranial direct current stimulation sensitizes the motor cortex to rapid-rate transcranial magnetic stimulation and controls the direction of aftereffects, Biol Psychiatry. 56 (2004) 634-639.

54. T. Murakami, F. Müller-Dahlhaus, M. Lu and U. Ziemann, Homeostatic metaplasticity of corticospinal excitatory and intracortical inhibitory neural circuits in human motor cortex, J. Physiol. 590 (2012) 5765-5781.

55. M. A. Nitsche and W. Paulus, Sustained excitability elevations induced by transcranial DC motor cortex stimulation in humans, Neurology. 57 (2001) 1899-1901.

56. A. Priori, A. Berardelli, S. Rona, N. Accornero and M. Manfredi, Polarization of the human motor cortex through the scalp, Neuroreport 9(10) (1998) 2257-2260.

57. H. R. Siebner et al., Preconditioning of lowfrequency repetitive transcranial magnetic stimulation with transcranial direct current stimulation: Evidence for homeostatic plasticity in the human motor cortex, J. Neurosci. 24(13) (2004) 33793385 .

58. B. Cengiz, N. Murase and J. C. Rothwell, Opposite effects of weak transcranial direct current stimulation on different phases of short interval intracortical inhibition (SICI), Exp. Brain Res. 225(3) (2013) 321-331.

59. V. Di Lazzaro, A. Oliviero, M. Meglio, B. Cioni, G. Tamburrini, P. Tonali and J. C. Rothwell, Direct demonstration of the effect of lorazepam on the excitability of the human motor cortex, Clin. Neurophysiol. 111 (2000) 794-799.

60. D. A. Edwards, L. Zhang and B. E. Alger, Metaplastic control of the endocannabinoid system at inhibitory synapses in hippocampus, Proc. Natl. Acad. Sci. USA 105(23) (2008) 8142-8147.

61. T. M. Fischer, D. E. J. Blazis, N. A. Priver and T. J. Carew, Metaplasticity at identified inhibitory synapses in aplysia, Nature 389(6653) (1997) 860865.

62. T. V. Ilic, F. Meintzschel, U. Cleff, D. Ruge, K. R. Kessler and U. Ziemann, Short-interval pairedpulse inhibition and facilitation of human motor cortex: The dimension of stimulus intensity, $J$. Physiol. 545(1) (2002) 153-167.

63. U. Ziemann, J. C. Rothwell and M. C. Ridding, Interaction between intracortical inhibition and facilitation in human motor cortex, J. Physiol. 496 (1996) 873-881.

64. V. Di Lazzaro, F. Ranieri, P. Profice, F. Pilato, P. Mazzone, F. Capone et al., Transcranial direct current stimulation effects on the excitability of corticospinal axons of the human cerebral cortex, Brain Stimul. 6(4) (2013) 641-643.

65. K. Monte-Silva, M. F. Kuo, S. Hessenthaler, S. Fresnoza, D. Liebetanz, W. Paulus et al., Induction of late LTP-like plasticity in the human motor cortex by repeated non-invasive brain stimulation, Brain Stimul. 6(3) (2013) 424-432.

66. K. Monte-Silva, M. F. Kuo, D. Liebetanz, W. Paulus and M. A Nitsche, Shaping the optimal repetition interval for cathodal transcranial direct current stimulation (TDCS), J Neurophysiol 103(4) (2010) 1735-1740.

67. M. A. Nitsche, K. Fricke, U. Henschke, A. Schlitterlau, D. Liebetanz and N. Lang et al., Pharmacological modulation of cortical excitability shifts induced by transcranial DC stimulation, J. Physiol. 553 (2003) 293-301.

68. C. J. Stagg, J. G. Best, M. C. Stephenson, J. O'Shea, M. Wylezinska, Z. T. Kincses et al., Polarity-sensitive modulation of cortical neurotransmitters by transcranial stimulation, J. Neurosci. 29(16) (2009) 5202-5206.

69. K. Wankerl, D. Weise, R. Gentner, J. J. Rumpf and J. Classen, L-type voltage-gated $\mathrm{Ca}^{2+}$ channels: A single molecular switch for long-term potentiation/long-term depression-like plasticity and activity-dependent metaplasticity in humans, J. Neurosci. 30 (2010) 6197-6204.

70. I. V. Sokolova and I. Mody, Silencing-induced metaplasticity in hippocampal cultured neurons, J. Neurophysiol. 100 (2008) 690-697.

71. C. A. Trasande and J. M. Ramirez, Activity deprivation leads to seizures in hippocampal slice cultures: Is epilepsy the consequence of homeostatic plasticity? J. Clin. Neurophysiol. 24 (2007) 154-164.

72. V. Di Lazzaro, U. Ziemann and R. N. Lemon, State of the art: Physiology of transcranial motor cortex stimulation, Brain Stimul. 1(4) (2008) 345362.

73. S. Groppa et al., A practical guide to diagnostic transcranial magnetic stimulation: Report of an IFCN committee, Clin. Neurophysiol. 123(5) (2012) 858-882.

74. A. Karabanov and H. R. Siebner, Unravelling homeostatic interactions in inhibitory and excitatory networks in human motor cortex, J. Physiol. $\mathbf{5 9 0 ( 2 2 ) ~ ( 2 0 1 2 ) ~ 5 5 5 7 - 5 5 5 8 . ~}$ 
75. S. H. Doeltgen and M. C. Ridding, Modulation of cortical motor networks following primed $\theta$ burst transcranial magnetic stimulation, Exp. Brain Res. 215(3-4) (2011) 199-206.

76. M. Hamada et al., Primary motor cortical metaplasticity induced by priming over the supplementary motor area J. Physiol. 587(20) (2009) 48454862.

77. M. Potter-Nerger et al., Inducing homeostatic-like plasticity in human motor cortex through converging corticocortical inputs, J. Neurophysiol. 102(6) (2009) 3180-3190.

78. P. Ragert et al., Modulation of effects of intermittent theta burst stimulation applied over primary motor cortex (M1) by conditioning stimulation of the opposite M1, J. Neurophysiol. 102(2) (2009) 766-773.

79. A. Vanhaudenhuyse, Q. Noirhomme, L. J. F. Tshibanda, M. A. Bruno, P. Boveroux, C. Schnakers, A. Soddu, V. Perlbarg, D. Ledoux, J. F. Brichant, G. Moonen, P. Maquet, M. D. Greicius, S. Laureys and M. Boly, Default network connectivity reflects the level of consciousness in non-communicative brain-damaged patients. Brain 133(1) (2010) 161-171.

80. M. M. Monti, M. Rosenberg, P. Finoia, E. Kamau, J. D. Pickard and A. M. Owen, Thalamo-frontal connectivity mediates top-down cognitive functions in disorders of consciousness, Neurology $\mathbf{8 4}(2)$ (2015) 167-173.

81. M. Rosanova, O. Gosseries, S. Casarotto, M. Boly, A. G. Casali, M. A. Bruno, M. Mariotti, P Boveroux, G. Tononi, S. Laureys and M. Massimini, Recovery of cortical effective connectivity and recovery of consciousness in vegetative patients, Brain 135(4) (2012) 1308-1320.

82. M. Di Filippo, A. Tozzi, C. Costa, V. Belcastro, B. Tantucci, B. Picconi and P. Calabresi, Plasticity and repair in the post-ischemic brain, Neuropharmacol 55 (2008) 353-362.

83. V. Crepel and Y. Ben-Ari, Intracellular injection of a $\mathrm{Ca}^{2+}$ chelator prevents generation of anoxic LTP, J. Neurophysiol. 75 (1996) 770-779.

84. Z. Kokaia, G. Andsberg, Q. Yan and O. Lindvall, Rapid alterations of BDNF protein levels in the rat brain after focal ischemia: Evidence for increased synthesis and anterograde axonal transport, Experi. Neurol. 154 (1998) 289-301.

85. S. H. Moosavi, P. H. Ellaway, M. Catley, M. J. Stokes and N. Haque, Corticospinal function in severe brain injury assessed using magnetic stimulation of the motor cortex in man, J. Neurol. Sci. 164 (1999) 179-186.

86. N. Lapitskaya, M. R. Coleman, J. F. Nielsen, O. Gosseries and A. M. de Noordhout, Disorders of consciousness: Further pathophysiological insights using motor cortex transcranial magnetic stimulation, Prog. Brain Res. 177 (2009) 191-200.
87. W. S. Huynh, A. V. Vucic, C. S. Krishnan, M. Lin, M. C. Hornberger and M. Kiernan, Longitudinal plasticity across the neural axis in acute stroke, Neurorehabil Neural Repair 27 (2013) 219-229.

88. R. J. Nudo, Neural bases of recovery after brain injury, J. Commun. Disord 44 (2011) 515-520.

89. V. Crepel, C. Hammond, P. Chinestra, D. Diabira and Y. Ben-Ari, A selective LTP of NMDA receptor-mediated currents induced by anoxia in CA1 hippocampal neurons, J. Neurophysiol. 70 (1993) 2045-2055.

90. C. C. Huang and K. S. Hsu, Nitric oxide signalling is required for the generation of anoxia-induced longterm potentiation in the hippocampus, Eur. J. Neurosci. 9 (1997) 2202-2206.

91. P. Calabresi, D. Centone, A. Pisani, L. Cupini and G Bernardi, Synaptic plasticity in the ischaemic brain, Lancet. Neurol. 2 (2003) 622-629.

92. M. Christova, D. Rafolt and E. Gallasch, Cumulative effects of anodal and priming cathodal TDCS on pegboard test performance and motor cortical excitability, Behav. Brain Res. 287 (2015) 27-33.

93. X. Zhang, D. G. Woolley, S. P. Swinnen, H. Feys, R. Meesen and N. Wenderoth, Changes in corticomotor excitability and intracortical inhibition of the primary motor cortex forearm area induced by anodal TDCS , PLoS One 9(7) (2014) e101496.

94. M. A. Bruno, A. Vanhaudenhuyse, A. Thibaut, G. Moonen and S. Laureys, From unresponsive wakefulness to minimally conscious PLUS and functional locked-in syndromes: Recent advances in our understanding of disorders of consciousness, J. Neurol. 258 (2011) 1373-1384.

95. R. Formisano, M. D'Ippolito, M. Risetti, A. Riccio, C. F. Caravasso, S. Catani et al., Vegetative state, minimally conscious state, akinetic mutism and Parkinsonism as a continuum of recovery from disorders of consciousness: An exploratory and preliminary study, Funct. Neurol. 26 (2011) 1-10.

96. R. Formisano, M. D'Ippolito and S. Catani, Functional locked-in syndrome as recovery phase of vegetative state, Brain Inj. 27 (2013) 1332.

97. R. Formisano, F. Pistoia and M. Sarà, Disorders of consciousness: A taxonomy to be changed? Brain Inj. 25 (2011) 638.

98. P. P. Mattogno, G. Barbagallo, G. Iacopino, G. Pappalardo, G. La Rocca, F. Signorelli, J. Zhong and M. Visocchi, Recovery from Chronic Diseases of Consciousness: State of the Art in Neuromodulation for persistent vegetative state and minimally conscious state, Acta. Neurochir. Suppl. 124 (2017) $19-25$.

99. J. J. Lemaire, A. Sontheimer, H. Nezzar, B. Pontier, J. Luauté, B. Roche, T. Gillart, J. Gabrillargues, S. Rosenberg, C. Sarret, F. Feschet, F. Vassal, D. Fontaine and J. Coste, Electrical modulation of neuronal networks in brain-injured patients with 
disorders of consciousness: A systematic review, Ann. Fr. Anesth. Reanim. 33(2) (2014) 88-97.

100. A. Estraneo, A. Pascarella, P. Moretta, O. Masotta, S. Fiorenza, G. Chirico, E. Crispino, V. Loreto and L. Trojano, Repeated transcranial direct current stimulation in prolonged disorders of consciousness: A double-blind cross-over study, J. Neurol. Sci. 375 (2017) 464-470.

101. A. Naro, P. Bramanti, A. Leo, M. Russo and R. S. Calabrò, Transcranial alternating current stimulation in patients with chronic disorder of consciousness: A possible way to cut the diagnostic gordian knot? Brain Topogr. 29(4) (2016) 623-644.

102. A. Thibaut, C. Di Perri, C. Chatelle, M. A. Bruno, M. A. Bahri, S. Wannez, A. Piarulli, C. Bernard, C. Martial, L. Heine, R. Hustinx and S. Laureys, Clinical response to tdcs depends on residual brain metabolism and grey matter integrity in patients with minimally conscious state, Brain Stimul. 8(6) (2015) 1116-1123.

103. A. Naro, R. S Calabrò, M. Russo, A. Leo, P. Pollicino, A. Quartarone and P. Bramanti, Can transcranial direct current stimulation be useful in differentiating unresponsive wakefulness syndrome from minimally conscious state patients? Restor. Neurol. Neurosci. 33(2) (2015) 159-176.

104. A. Thibaut, M. A. Bruno, D. Ledoux, A. Demertzi and S. Laureys, TDCS in patients with disorders of consciousness: Sham-controlled randomized double-blind study, Neurology 82(13) (2014) 11121118.

105. E. Angelakis, E. Liouta, N. Andreadis, S. Korfias, P. Ktonas, G. Stranjalis and D. E. Sakas, Transcranial direct current stimulation effects in disorders of consciousness, Arch. Phys. Med. Rehabil. 95(2) (2014) 283-289.

106. P. Kadam and S. Bhalerao, Sample size calculation, Int. J. Ayurveda Res. 1(1) (2010) 55-57.

107. S. B. Hulley, S. R. Cummings, W. S. Browner, D. Grady and T. B. Newman, Designing Clinical Research: An Epidemiologic Approach, 4th edn. (Lippincott Williams \& Wilkins, Philadelphia, PA, 2013), p. 73.

108. N. D. Lant, L. E Gonzalez-Lara, A. M. Owen and D. Fernández-Espejo, Relationship between the anterior forebrain mesocircuit and the default mode network in the structural bases of disorders of consciousness, Neuroimage Clin. 10 (2016) 27-35.

109. N. D. Schiff, Recovery of consciousness after brain injury: A mesocircuit hypothesis, Trends Neurosci. 33(1) (2010) 1-9.

110. J. Reis, O. B. Swayne, Y. Vandermeeren, M. Camus, M. A. Dimyan, M. Harris-Love et al., Contribution of transcranial magnetic stimulation to the understanding of cortical mechanisms involved in motor control, J. Physiol. 586(2) (2008) 325-351.

111. J. Annen, L. Heine, E. Ziegler, G. Frasso, M. Bahri, C. Di Perri et al., Function-structure connectivity in patients with severe brain injury as measured by MRI-DWI and FDG-PET, Hum. Brain Mapp. 37(11) (2016) 3707-3720.

112. M. Boly, M. Massimini, M. I. Garrido, O. Gosseries, Q. Noirhomme, S. Laureys and A. Soddu, Brain connectivity in disorders of consciousness, Brain Connect. 2(1) (2012) 1-10.

113. C. Di Perri, M. A. Bahri, E. Amico, A. Thibaut, L. Heine, G. Antonopoulos et al., Neural correlates of consciousness in patients who have emerged from a minimally conscious state: A cross-sectional multimodal imaging study, Lancet. Neurol. 15(8) (2016) 830-842.

114. D. Godwin, R. L. Barry and R. Marois, Breakdown of the brain's functional network modularity with awareness, Proc. Natl. Acad. Sci. USA 112 (12) (2015) 3799-3804.

115. S. Silva, F. de Pasquale, C. Vuillaume, B. Riu, I. Loubinoux, T. Geeraerts et al., Disruption of posteromedial large-scale neural communication predicts recovery from coma, Neurology $\mathbf{8 5}(23)$ (2015) 2036-2044.

116. S. Laureys, S. Goldman, C. Phillips, P. Van Bogaert, J. Aerts, A. Luxen et al., Impaired effective cortical connectivity in vegetative state: Preliminary investigation using PET, Neuroimage $\mathbf{9}(4)$ (1999) 377-382.

117. C. M. Butefisch, B. C. Davis, S. P. Wise, L. Sawaki, L. Kopylev, J. Classen and L. G. Cohen, Mechanisms of use-dependent plasticity in the human motor cortex, Proc. Natl. Acad. Sci. USA 97 (2000) 3661-3665.

118. V. Di Lazzaro, D. Restuccia, A. Oliviero, P. Profice, L. Ferrara, A. Insola, P. Mazzone, P. Tonali and J. C. Rothwell, Effects of voluntary contraction on descending volleys evoked by transcranial stimulation in conscious humans, J Physiol. 508(2) (1998) 625-633.

119. J. Fombellida, I. Martín-Rubio and D. Andina, Application of artificial metaplasticity fundamentals to WBCD breast cancer database classification method, in World Automation Congress $(W A C)$ (IEEE, Rio Grande, Puerto Rico, 2015) doi: 10.1109/WAC.2016.7582981.

120. D. Andina and F. J. Ropero-Peláez, On the biological plausibility of artificial metaplasticity learning algorithm, Neurocomputing 114 (2013) 32-35.

121. A. Marcano-Cedeño, P. Chausa, A. García, C. Cáceres, J. M. Tormos and E. J. Gómez, Artificial metaplasticity prediction model for cognitive rehabilitation outcome in acquired brain injury patients, Artif. Intell. Med. 58(2) (2013) 91-99. 